\title{
A Method to Determination of Lead Ions in Aqueous Samples: Ultrasound-Assisted Dispersive Liquid-Liquid Microextraction Method Based on Solidification of Floating Organic Drop and Back-Extraction Followed by FAAS
}

\author{
Çiğdem Arpa $\mathbb{D}$ and Itır Aridaşir \\ Chemistry Department, Hacettepe University, Beytepe, 06800 Ankara, Turkey \\ Correspondence should be addressed to Çiğdem Arpa; carpa@hacettepe.edu.tr
}

Received 20 March 2018; Accepted 4 July 2018; Published 1 August 2018

Academic Editor: Valdemar Esteves

Copyright (C) 2018 Çiğdem Arpa and Itır Aridaşir. This is an open access article distributed under the Creative Commons Attribution License, which permits unrestricted use, distribution, and reproduction in any medium, provided the original work is properly cited.

\begin{abstract}
Ultrasound-assisted dispersive liquid-liquid microextraction method based on solidification of floating organic drop and backextraction (UA-DLLME-SFO-BE) technique was proposed for preconcentration of lead ions. In this technique, two SFODME steps are applied in sequence. The classical SFODME was applied as the first step and then the second (back-extraction) step was applied. For the classical SFODME, Pb ions were complexed with Congo red at $\mathrm{pH} 10.0$ and then extracted into 1-dodecanol. After this stage, a second extraction step was performed instead of direct determination of the analyte ion in the classical method. For this purpose, the organic phase containing the extracted analyte ions is treated with $1.0 \mathrm{~mol} \cdot \mathrm{L}^{-1} \mathrm{HNO}_{3}$ solution and then exposed to ultrasonication. So, the analyte ions were back-extracted into the aqueous phase. Finally, the analyte ions in the aqueous phase were determined by FAAS directly. Owing to the second extraction step, a clogging problem caused by 1-dodecanol during FAAS determination was avoided. Some parameters which affect the extraction efficiency such as $\mathrm{pH}$, volume of extraction solvent, concentration of complexing agent, type, volume, and concentration of back-extraction solvent, effect of cationic surfactant addition, effect of temperature, and so on were examined. Performed experiments showed that optimum $\mathrm{pH}$ was 10.0, 1-dodecanol extraction solvent volume was $75 \mu \mathrm{L}$, back-extraction solvent was $500 \mu \mathrm{L}, 1.0 \mathrm{~mol} \cdot \mathrm{L}^{-1} \mathrm{HNO}_{3}$, extraction time was 4 min, and extraction temperature was $40^{\circ} \mathrm{C}$. Under optimum conditions, the enhancement factor, limit of detection, limit of quantification, and relative standard deviation were calculated as $81,1.9 \mu \mathrm{g} \cdot \mathrm{L}^{-1}, 6.4 \mu \mathrm{g} \cdot \mathrm{L}^{-1}$, and $3.4 \%$ (for $25 \mu \mathrm{g} \cdot \mathrm{L}^{-1} \mathrm{~Pb}^{2+}$ ), respectively.
\end{abstract}

\section{Introduction}

Lead is highly toxic and potentially dangerous to living organisms because of the accumulation ability in the vital organs. Long-term exposure to lead causes cumulative poisoning which leads to central nervous system damages $[1,2]$. On account of this, even at low concentration, determination and controlling of lead content are crucial [3]. However, because of their complex matrix and trace concentration, determination of heavy metals in many real samples is a difficult analytical task and requires sensitive detection techniques and probably a preconcentration procedure [4].

Nowadays, for determination of trace heavy metals, atomic absorption spectrometry equipped with flame (FAAS) or graphite furnace (ETAAS) and inductively coupled plasma emission spectrometry (ICP) [5-7] are widely used analytical techniques. Among these techniques, although flame atomic absorption spectrometry is commonly used for heavy metal determination, its sensitivity is not enough to direct determination of trace and ultra-trace amount of heavy metals in real samples; therefore, some pretreatment procedures, such as separation and preconcentration, are needed [8]. Several sample preparation methods for the preconcentration and separation of heavy metals have been developed. Solid-phase extraction (SPE) [9], solid-phase microextraction (SPME) [10], dispersive liquid-liquid microextraction (DLLME) [11], and cloud point extraction (CPE) $[12,13]$ are some of these methods [14]. 
Recently, the solidified floating organic drop microextraction (SFODME) [15-17] has been attracted more attention and properly utilized as an effective method for heavy metal extraction and preconcentration. In this technique, a free microdrop of the organic solvent which has a low melting point (in the range of $10-30^{\circ} \mathrm{C}$ ) and a density lower than water is gently dropped to the stirred sample solution. Under the appropriate stirring conditions, the organic microdrop floats on the aqueous sample and species, which have a hydrophobic character, are extracted into this phase. After completion of the extraction, the sample vial is placed in an ice bath, and the floated drop solidifies. After solidification, the organic drop is easily transferred to a conical tube and melted there. Finally, the analyte in the extraction phase is determined by using FAAS. The SFODME method needs very small volumes of the harmful organic solvent, and this makes the method simple, fast, cheap, and environmental friendly [18]. Application of ultrasonic energy to a solution causes acoustic cavitation. Cavitation is the formation and then immediate implosion of bubbles in a liquid. When high temperatures and pressures are produced at the interface of the bubble and other phases, an increase in chemical reactivity occurs [19]. Hence, combination of microextraction processes with ultrasound energy accelerates the extraction step and improves the efficiency of preconcentration. This combined technique is called as ultrasound-assisted emulsification-microextraction (USAEME) and bears all the advantages of both methods.

Besides all these advantages mentioned above, SFODME has some important disadvantages: selected extracting solvent should not be volatile and toxic, and its melting point should be close to or below room temperature [20]. Having a melting point near room temperature also means that the extracting solvent freezes easily at room temperature. After solidification, the microdrop is transferred to a conical vial, is diluted with an appropriate solvent to a certain volume, and is then analyzed for determination of heavy metal concentration. But, unfortunately, after detection of the analyte, the solvent residues freeze again in the capillaries, tubes, and pipes of the FAAS instrument, and this causes clogging of the sample introduction path and drainage path of the instrument. (Especially, when the room temperature is slightly below $24^{\circ} \mathrm{C}$ in winter). Remedy of clogging in the system requires washing the pipes with plenty of hot water and alcohol solution several times, which is a time- and chemical-consuming process. In addition to clogging problems, 1-dodecanol has a background signal, which interferes with the analyte signal. To eliminate this problem, the back-extraction step can be applied [1].

In this ultrasound-assisted dispersive liquid-liquid microextraction method based on solidification of floating organic drop and back-extraction (UA-DLLME-SFO-BE) technique, two solidified floating organic drop microextraction (SFODME) steps are performed in sequence. In the first step, the following conventional SFODME procedure is applied: the extraction solvent is added into the solution including heavy metal ions that form hydrophobic complexes with suitable complexing agent. After applying ultrasound energy, extraction occurs, and hydrophobic

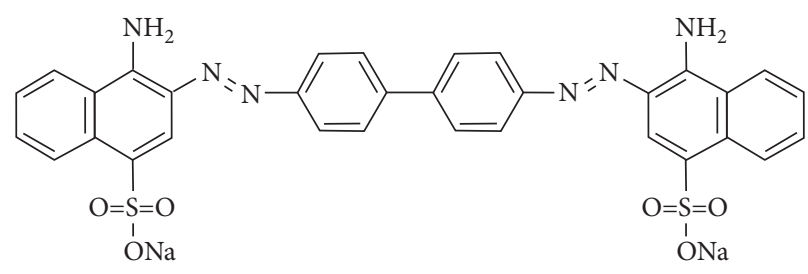

Figure 1: Molecular structure of CR.

analyte species are transferred into the organic solvent. At this stage, instead of direct analysis of the extraction phase, a second SFODME round is performed, in which the extraction phase is treated with diluted acid solution, and after applying ultrasound, interested analyte is back-extracted into the aqueous phase. At the end of second SFODME, the obtained aqueous solution, which includes the analyte, is injected to the FAAS. The second extraction step provides the elimination of the clogging problem of the organic extraction solvent.

In this study, we developed a UA-DLLME-SFO-BE method for the determination of $\mathrm{Pb}^{2+}$ ions in aqueous samples. For this purpose, Congo red (CR) is used as a complexing agent to obtain hydrophobic $\mathrm{Pb}^{2+}$ complexes. $\mathrm{CR}-\mathrm{Pb}^{2+}$ complexes are extracted into 1-dodecanol and back-extracted into aqueous nitric acid solution, which eliminates the drawbacks of the organic extraction phase as mentioned above. CR (3,3'-[[1,1' biphenyl]-4,4'-diylbis(azo)] bis[4-amino-1-naphthalene-sulfonic acid] disodium salt) is a sulfonated bis-azo dye [21]. As seen from Figure 1, $\mathrm{CR}$ has azo, sulfonate, and amino groups, and these groups provide two different donor atoms: one is $\mathrm{N}$ from azo or amino groups and other one is $\mathrm{O}$ from sulfonate groups. Complexation between metals and CR may occur through these donor atoms $[22,23]$.

There are two special features at the heart of the study: (i) implementation of ultrasound energy shortens the extraction time and improves the extraction efficiency; (ii) by performing a second extraction step, drawbacks of 1-dodecanol in conventional SFODME (clogging of pipes and tubings of instrument and background signal) are eliminated. In order to fully characterize the proposed method, several parameters were explored and optimized.

\section{Experimental}

2.1. Reagents and Standard Solutions. $1000 \mathrm{mg} \cdot \mathrm{L}^{-1}$ stock standard solution of lead was prepared by dissolving a necessary mass of $\mathrm{Pb}\left(\mathrm{NO}_{3}\right)_{2}$ in a small amount of deionized water and diluting it to the appropriate volume. All solutions were prepared with deionized water $\left(18.1 \mathrm{M} \Omega \mathrm{m}^{-1}\right)$ obtained from a Millipore Simplicity UV purification system. Working standard solutions were prepared daily by serial dilutions of the stock solution with deionized water just before analysis. The chelating agent, $0.1 \%$ CR solution, was prepared by dissolving the appropriate amount of $\mathrm{CR}$ (purchased from $\mathrm{BDH}$, Poole, England) in acetone. $\mathrm{Na}_{2} \mathrm{HPO}_{4} / \mathrm{NaOH}$ (purchased from Merck, Darmstadt, Germany) buffer system was used to adjust the 


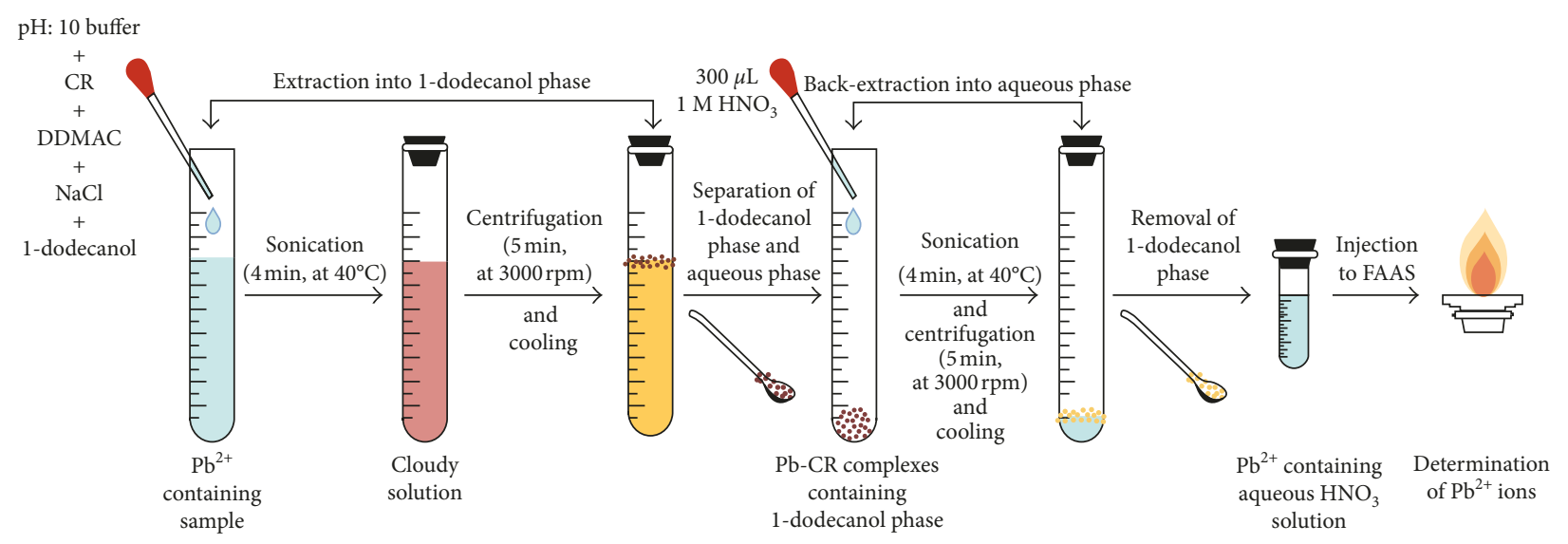

Figure 2: Schematic representation of UA-DLLME-SFO-BE procedure.

sample $\mathrm{pH}$ to 10.0. 1-dodecanol, used as an extraction solvent, was obtained from Merck, and didecyldimethyl ammoniumchloride (DDMAC) was purchased from SigmaAldrich. A solution of $8 \%(\mathrm{v} / \mathrm{v})$ DDMAC was prepared by dissolving proper amount of DDMAC in water. All reagents used were of analytical reagent grade. All the solutions were prepared by using deionized water. In order to eliminate possible contamination, all glassware was immersed into $10 \%$ hydrochloric acid for at least $24 \mathrm{~h}$ and then rinsed three times with deionized water.

2.2. Instrument. A Perkin Elmer Analyst atomic absorption spectrometer equipped with a lead hollow cathode lamp (Perkin Elmer) as the radiation source was used for determination of lead. The analytical wavelength $(283.3 \mathrm{~nm})$, slit width $(0.7 \mathrm{~nm})$, and lamp current $(28 \mathrm{~mA})$ were used as recommended by the manufacturer. All $\mathrm{pH}$ measurements were carried out with an Isolab Laborgeräte $\mathrm{GmbH}$ digital $\mathrm{pH}$ meter equipped with a $\mathrm{pH}$ electrode. A Hettich Eba 21 model centrifuge was used to accelerate the phase separation. A $53 \mathrm{kHz}, 100 \mathrm{~W}$ temperature-controlled ultrasonic bath (Kudos SK3310LHC) was used in the ultrasoundassisted emulsification process of the method.

2.3. Procedure for UA-DLLME-SFO-BE. The UA-DLLMESFO-BE method includes two SFODME steps. In the first step, $25.0 \mathrm{~mL} \mathrm{~Pb}^{2+}$ solution or water samples, $2 \mathrm{~mL}$ of $\mathrm{Na}_{2} \mathrm{HPO}_{4} / \mathrm{NaOH}$ buffer solution, $1 \mathrm{~mL}$ of $0.5 \%$ (w/v) CR solution, $100 \mu \mathrm{L} 8 \%(\mathrm{v} / \mathrm{v})$ DDMAC, and $0.1 \mathrm{~g} \mathrm{NaCl}$ were mixed. Then, $75 \mu \mathrm{L}$ of 1 -dodecanol was added. The conical tube was sonicated for $4 \mathrm{~min}$ at $40^{\circ} \mathrm{C}$ to ensure complete extraction. At this step, the lead ions reacted with CR and extracted into 1-dodecanol. With the addition of DDMAC, $\mathrm{Pb}-\mathrm{CR}$ complex gained more hydrophobic character and was more extractable into the 1-dodecanol phase. With the aid of centrifugation ( $5 \mathrm{~min}$ at $3000 \mathrm{rpm}$ ), very small droplets of the 1-dodecanol group were brought together and collected at the vicinity of sample solution. After cooling of the test tube in the refrigerator, the 1-dodecanol phase was solidified, and this solidified phase was transferred into another conical tube. At this stage, instead of adding a diluent and determination of $\mathrm{Pb}^{2+}$, a second SFODME procedure was applied. For this purpose, the 1-dodecanol phase containing $\mathrm{Pb}-\mathrm{CR}$ complexes was treated with $500 \mu \mathrm{L}$ of $1 \mathrm{~mol} \cdot \mathrm{L}^{-1} \mathrm{HNO}_{3}$ solution. After sonication for $4 \mathrm{~min}$ at $40^{\circ} \mathrm{C}$, the tube was centrifuged for $5 \mathrm{~min}$ at $3000 \mathrm{rpm}$. At this stage, $\mathrm{Pb}^{2+}$ ions were transferred from the 1-dodecanol phase to the aqueous $\mathrm{HNO}_{3}$ phase. Finally, the supernatant was introduced into FAAS by direct nebulization for $\mathrm{Pb}^{2+}$ analysis, and the blank was also treated in the same way. Schematic representation of the proposed procedure is shown in Figure 2.

\section{Results and Discussion}

In order to obtain the maximum extraction efficiency and the highest enhancement factor, several parameters that influence the metal-ligand formation and the extraction conditions were studied. In the course of optimization experiments, $100 \mu \mathrm{g} \cdot \mathrm{L}^{-1}$ of $\mathrm{Pb}^{2+}$ working solutions were utilized. After obtaining optimum conditions, the $\mathrm{Pb}^{2+}$ content of certified reference materials and some natural water samples were determined by using these optimum conditions.

3.1. Selection of the Extraction Solvent and Effect of Its Volume on Extraction. In the optimization of the SFODME process, the choice of the proper extraction solvent is one of the important steps. For this method, the extraction solvent must have the following features: (1) being immiscible with water, (2) having low volatility, which provides a stable character during the extraction step, (3) having a considerable extraction efficiency, (4) having a lower density than that of water, (5) having a melting point around room temperature (in the range of $10-30^{\circ} \mathrm{C}$ ), and (6) having a low toxicity level [24]. For this purpose, 1-dodecanol (density: $0.8201-0.8309 \mathrm{~g} \cdot \mathrm{mL}^{-1}$; melting point: $24^{\circ} \mathrm{C}$ ) was chosen as the extracting solvent because of its sensitivity, stability, low water solubility, low vapor pressure, and low price.

To investigate the effect of the extraction solvent volume on extraction efficiency, 1-dodecanol volumes were changed in the range of $10-250 \mu \mathrm{L}$, while other parameters were kept at optimum values. It was not possible to work with volumes 


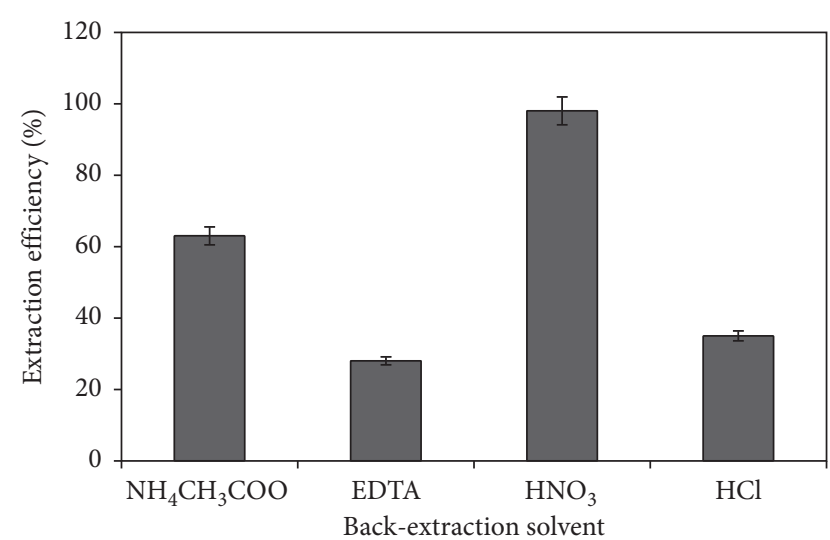

FIGURE 3: Effect of back-extraction solvent type. Conditions: $25 \mathrm{~mL}$ of $100 \mu \mathrm{g} \cdot \mathrm{L}^{-1} \mathrm{~Pb}^{2+}, 0.5 \%$ (w/v) CR, 0.03\% (v/v) DDMAC, $0.1 \mathrm{~g}$ $\mathrm{NaCl}, 75 \mu \mathrm{L}$ 1-dodecanol, $4 \mathrm{~min}$ extraction time, and $40^{\circ} \mathrm{C}$ extraction temperature.

less than $10 \mu \mathrm{L}$. The extraction efficiency values (calculated from absorbance values obtained various volumes of 1-dodecanol) showed that initially increasing the volume of 1-dodecanol in the range of $10-50 \mu \mathrm{L}$ causes increase in the extraction efficiency, and then the extraction efficiency remained constant at $98 \%$ in the range of 75-100 $\mu \mathrm{L}$. Finally, extraction efficiencies slightly decreased by the volumes greater than $100 \mu \mathrm{L}$. Therefore, in the subsequent studies, $75 \mu \mathrm{L}$ was chosen as the optimum volume for 1-dodecanol.

3.2. Selection and Effect of Back-Extraction Solvent. In the second step of the procedure, several back-extraction solvents were tried to extract $\mathrm{Pb}^{2+}$ ions from their $\mathrm{Pb}-\mathrm{CR}$ complexes into the aqueous phase in order to eliminate drawbacks of the 1-dodecanol phase. For this purpose, aqueous solutions of EDTA, $\mathrm{NH}_{4} \mathrm{CH}_{3} \mathrm{COO}, \mathrm{HCl}$, and $\mathrm{HNO}_{3}$ were examined as back-extraction solvents. During this optimization study, other experimental conditions were adjusted to optimum values. Among all these solvents, $\mathrm{HNO}_{3}$ gave the superior extraction efficiency (>96\%) and therefore, was chosen as the back-extraction solvent (Figure 3). After experiments, which were performed to explore the effects of $\mathrm{HNO}_{3}$ concentration and volume on the extraction efficiency, optimum $\mathrm{HNO}_{3}$ concentration and volume were found as $1 \mathrm{M}$ and $500 \mu \mathrm{L}$, respectively. (During these optimization experiments, concentration and volume of $\mathrm{HNO}_{3}$ were varied in the range of $0.1 \mathrm{M}-2.0 \mathrm{M}$ and $100 \mu \mathrm{L}-1000 \mu \mathrm{L}$, respectively, and other parameters were kept at optimum values).

3.3. Effect of $p H$. Complex formation interaction between ligand and metal, and hence extraction efficiency, is $\mathrm{pH}$ dependent $[25,26]$. The effect of $\mathrm{pH}$ on the formation and extraction of $\mathrm{Pb}-\mathrm{CR}$ complex was investigated at the $\mathrm{pH}$ range of 3.0-12.0 by adding appropriate buffer solutions. During these experiments, other parameters were adjusted to their optimum values. Obtained results are shown in Figure 4. As seen in this figure, the extraction efficiency of

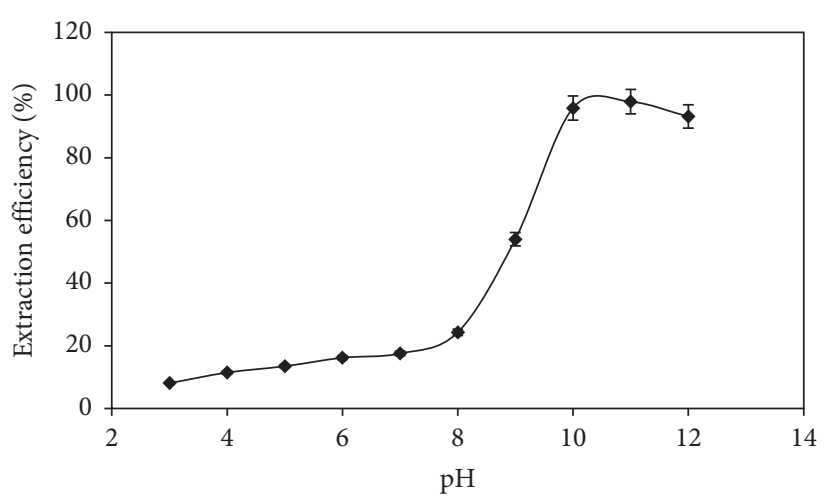

Figure 4: Effect of $\mathrm{pH}$ on the extraction efficiency. Conditions: $25 \mathrm{~mL}$ of $100 \mu \mathrm{g} \cdot \mathrm{L}^{-1} \mathrm{~Pb}^{2+}, 0.5 \%$ (w/v) CR, 0.03\% (v/v) DDMAC, $0.1 \mathrm{~g} \mathrm{NaCl}, 75 \mu \mathrm{L}$ 1-dodecanol, 4 min extraction time, and $40^{\circ} \mathrm{C}$ extraction temperature.

lead with $\mathrm{CR}$ into 1-dodecanol was maximized and remained nearly constant $(>98 \%)$ in the $\mathrm{pH}$ range of 10.0-11.0. Decreasing extraction efficiencies at low $\mathrm{pH}$ values were probably due to the competition of hydrogen ions with lead ions in the complex formation reaction with $\mathrm{CR}$. Therefore, the $\mathrm{pH}$ of aqueous solution was adjusted at around $\mathrm{pH} 10.0$.

3.4. Effect of Amount of CR. The extraction efficiency of the analyte depends on the distribution ratio of the metal chelate between the organic and aqueous phases [27]. At a constant aqueous phase $\mathrm{pH}$, the value of the distribution ratio and therefore the extraction efficiency increases to a certain value with the increasing amount of the chelate. The influence of $\mathrm{CR}$ amount on the extraction efficiency of lead was studied using different volumes of $0.1 \%(\mathrm{w} / \mathrm{v})$ CR solution ranging from $0.1 \mathrm{~mL}$ to $2.0 \mathrm{~mL}$, while other parameters were kept at their optimum values. According to the results obtained after optimization experiments, the extraction efficiency was increased with the increase of $\mathrm{CR}$ volume up to $0.5 \mathrm{~mL}$ and then remained constant at a value greater than $98 \%$. In other words, the extraction efficiency was constant when the CR volume was higher than $0.5 \mathrm{~mL}$, indicating complete complexation. Therefore, $0.5 \mathrm{~mL}$ of $0.1 \%$ (w/v) CR solution was chosen as the optimum value for subsequent studies.

3.5. Effect of DDMAC Concentration. In general, as mentioned before, species to be extracted into 1-dodecanol should have a hydrophobic character, and this is the greatest limitation of all the SFODME techniques. Consequently, hydrophilic and polar characters of the extracted compounds lower the extraction efficiency. To cope with this limitation, a cationic surfactant, DDMAC, has been introduced to the sample solution to attain sites with hydrophobic solubilizing properties that would make the extraction of metal chelates with hydrophilic character easier [28]. By adding DDMAC, the Pb-CR complex was possessed of more hydrophobic features, and thus, the complex was more extractable into 1-dodecanol. As a result, a higher extraction efficiency factor was obtained. In order to explore 


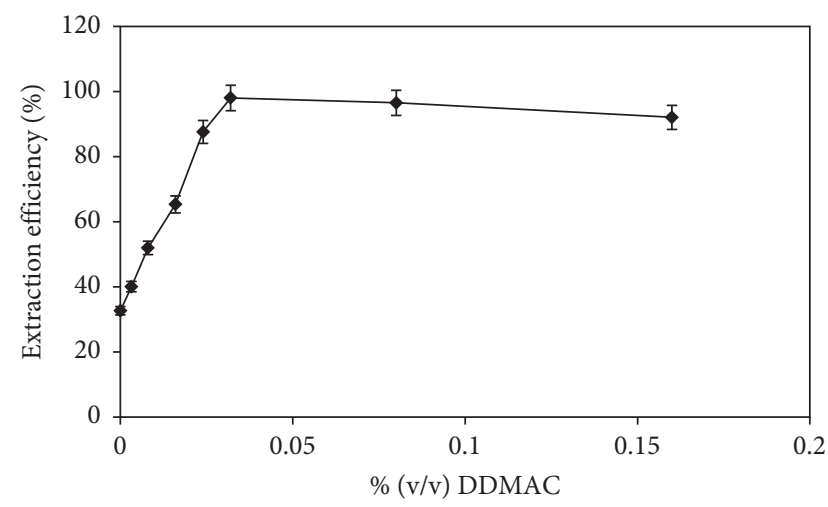

FIGURE 5: Effect of DDMAC concentration on the extraction efficiency. Conditions: $25 \mathrm{~mL}$ of $100 \mu \mathrm{g} \cdot \mathrm{L}^{-1} \mathrm{~Pb}^{2+}, \mathrm{pH}: 11.0,0.5 \%(\mathrm{w} / \mathrm{v})$ $\mathrm{CR}, 0.1 \mathrm{~g} \mathrm{NaCl}, 75 \mu \mathrm{L}$ 1-dodecanol, 4 min extraction time, and $40^{\circ} \mathrm{C}$ extraction temperature.

the effect of DDMAC concentration on the extraction efficiency, various amounts of DDMAC solution in the range of $0.003 \%$ to $0.16 \%$ were evaluated. The obtained results given in Figure 5 showed that with the increasing DDMAC concentration, the extraction efficiency increased up to $0.03 \%(\mathrm{v} / \mathrm{v})$ and then remained constant up to $0.16 \%(\mathrm{v} / \mathrm{v})$. So, a DDMAC concentration of $0.03 \%(\mathrm{v} / \mathrm{v})$ was selected in the following experiments. Note that, the extraction efficiencies were about $30 \%$ and $98 \%$ in the absence and in the presence of DDMAC, respectively. So, it can be concluded that the presence of DDMAC enhances the extraction efficiency by more than 3 folds.

3.6. Effect of Salt Addition. Increase in ionic strength resulting from salt addition causes two opposite effects on the extraction efficiency: (1) the physical properties of the Nernst diffusion film can change by the presence of dissolved salt in water, and consequently, the diffusion rate of the analyte into the drop can decrease [29]; (2) the salting-out effect can cause an increase in the extraction efficiency [30]. In order to investigate the effect of ionic strength arising from salt addition, on performance of UA-DLLME-SFO-BE, various experiments were performed by adding varying amounts of $\mathrm{NaCl}$ from $0 \%$ to $4 \%(\mathrm{w} / \mathrm{v})$. Other experimental parameters were kept constant. The results showed a gradual increase in the extraction efficiency of the $\mathrm{Pb}$ ions with increased $\mathrm{NaCl}$ amount up to $0.4 \%(\mathrm{w} / \mathrm{v})$ and then remained constant when salt concentration is between $0.4 \%$ and $2 \%$. However, a further increase in the salt concentration caused a decrease in the extraction efficiency. Thus, a concentration of $0.4 \%(\mathrm{w} / \mathrm{v})$ of $\mathrm{NaCl}$ was chosen as the optimum value.

\subsection{Effects of Temperature and Duration on Extraction and} Back-Extraction. The temperature affects both the solubility of the organic extraction solvent in the aqueous phase and the emulsification process. Thus, it also affects the mass transfer and the extraction efficiency [28]. If the extraction temperature is lower than $25^{\circ} \mathrm{C}$, the selected extraction solvent 1-dodecanol (melting point: $22-24^{\circ} \mathrm{C}$ ) becomes more
TABLE 1: Tolerance limits of interfering ions in the determination of $50 \mu \mathrm{g} \cdot \mathrm{L}^{-1}$ of $\mathrm{Pb}^{2+}$.

\begin{tabular}{lc}
\hline $\mathrm{M}^{\mathrm{a}}$ & {$\left[\mathrm{Pb}^{2+}\right] /[\mathrm{M}]$} \\
\hline $\mathrm{Na}^{+}$ & $>1: 5000$ \\
$\mathrm{Mg}^{2+}$ & $>1: 5000$ \\
$\mathrm{Fe}^{3+}$ & $1: 500$ \\
$\mathrm{Cd}^{2+}$ & $1: 1500$ \\
$\mathrm{NH}_{4}^{+}$ & $>1: 5000$ \\
$\mathrm{Zn}^{2+}$ & $1: 500$ \\
$\mathrm{Co}^{2+}$ & $1: 100$ \\
$\mathrm{Cr}^{3+}$ & $1: 1000$ \\
$\mathrm{Ni}^{2+}$ & $1: 100$ \\
$\mathrm{SCN}^{-}$ & $1: 2000$ \\
$\mathrm{Mn}^{2+}$ & $1: 500$ \\
$\mathrm{CO}_{3}{ }^{2-}$ & $1: 1000$ \\
$\mathrm{CrO}_{4}{ }^{2-}$ & $1: 2000$ \\
$\mathrm{Cu}^{2+}$ & $1: 500$ \\
$\mathrm{Al}^{3+}$ & $1: 100$ \\
\hline
\end{tabular}

${ }^{\mathrm{a}}$ Interfering ion.

viscous in the extraction medium and the emulsification does not occur properly. On the contrary, at higher temperatures, the solubility and volatility of 1-dodecanol increase, and this leads to decrease in the extraction efficiency. In addition, higher temperatures cause decomposition of the metal complexes. In order to get a satisfying extraction efficiency, the extraction temperature and incubation time required to complete extraction should be optimized. The effect of the extraction temperature (ultrasonic bath temperature) and duration was explored in the range of $20-60^{\circ} \mathrm{C}$ and 1-8 min, respectively. It was found that a temperature of $40^{\circ} \mathrm{C}$ and a time of $4 \mathrm{~min}$ for sonication were adequate to achieve an optimum extraction efficiency. Same temperature and time values, $40^{\circ} \mathrm{C}$ and a $4 \mathrm{~min}$, were used for backextraction in UA-DLLME-SFO-BE.

3.8. Effect of Interfering Ions. Other ions except $\mathrm{Pb}$ in natural samples can affect the extraction efficiency. In order to explore the effect of coexisting ions, $25 \mathrm{~mL}$ solutions containing $50 \mu \mathrm{g} \cdot \mathrm{L}^{-1} \mathrm{~Pb}^{2+}$ ions together with foreign ions were processed according to the developed procedure. If an added foreign ion caused $\pm 5 \%$ variation in the absorbance value of analyte, then it was considered as interfering species. The obtained results are summarized in Table 1. According to the given results, the method has a good tolerance to coexisting ions.

3.9. Analytical Performance of the Method. The calibration graphs were linear in the range of $10-500 \mu \mathrm{g} \cdot \mathrm{L}^{-1}$ lead under the optimum conditions of the proposed UA-DLLME-SFO$\mathrm{BE}$ procedure. The regression equation for lead determination after microextraction was $\mathrm{A}=4.22 \times 10^{-4} \mathrm{C}-2.81 \times 10^{-2}$, where $\mathrm{A}$ is the absorbance and $\mathrm{C}$ is the metal ion concentration in solution $\left(\mu \mathrm{g} \cdot \mathrm{L}^{-1}\right)$. The correlation coefficient of the calibration curve equation was 0.994 . The equation obtained by direct aspiration in FAAS without the microextraction procedure was $\mathrm{A}=5.22 \times 10^{-6} \mathrm{C}+1.79 \times 10^{-4}$, with linear range between 2,000 and $5,000 \mu \mathrm{g} \cdot \mathrm{L}^{-1}$ with the correlation coefficient of 0.999 . The enhancement factor calculated as the ratio of the 
TABLE 2: Analytical characteristics of the proposed method.

\begin{tabular}{lc}
\hline Analytical feature & Value \\
\hline Enhancement factor (EF) & 81 \\
Limit of detection (LOD) $\left(\mu \mathrm{g} \cdot \mathrm{L}^{-1}\right)(n=10)$ & 1.9 \\
Limit of quantitation (LOQ) $\left(\mu \mathrm{g} \cdot \mathrm{L}^{-1}\right)(n=10)$ & 6.4 \\
Linear range $\left(\mu \mathrm{g} \cdot \mathrm{L}^{-1}\right)$ & $10-500$ \\
Precision (\%RSD) $\left(n=10\right.$, for $\left.25 \mu \mathrm{g} \cdot \mathrm{L}^{-1} \mathrm{~Pb}^{2+}\right)$ & 3.4 \\
\hline
\end{tabular}

slope of calibration curves of the analyte after microextraction to that of prior microextraction was found as 81 .

As an indication of precision, the relative standard deviation (RSD) was calculated for 10 replicate measurements by using $25 \mu \mathrm{g} \cdot \mathrm{L}^{-1} \mathrm{~Pb}^{2+}$ and was found to be less than $3.4 \%$. The limit of detection (LOD), defined as the concentration ratio of three times the standard deviation of the blank signal and the slope of the calibration graph after preconcentration, was found as $1.9 \mu \mathrm{g} \cdot \mathrm{L}^{-1}$. The limit of quantification (LOQ) was the lowest level of the analyte that can be accurately and precisely measured. LOQ, defined as the concentration ratio of ten times the standard deviation of the blank signal and the slope of the calibration graph after preconcentration, was found as $6.4 \mu \mathrm{g} \cdot \mathrm{L}^{-1}$. Table 2 summarizes some analytical figures of the method.

3.10. Accuracy of the Method. In order to prove the performance, the proposed method, a certified reference material (TM-61.2, fortified water), was used and recovery values were calculated. The certified concentration value for $\mathrm{Pb}(\mathrm{II})$ ions was $61.4 \mu \mathrm{g} \cdot \mathrm{L}^{-1}$. Recovery values were calculated as the averages of three parallel experiments and found as $99 \%$. This value proves the satisfying consistency between the obtained results and certified value. These results also show that the developed method was successful for the determination of lead.

3.11. Analysis of Real Samples. In order to evaluate the validation of the method, the recovery experiments were performed by spiking different water samples such as tap (Ankara, Turkey) and lake (Ankara, Turkey) water samples. During these experiments, different amounts of lead were added to these water samples and the optimized method was applied. Obtained results are given in Table 3. As understood from the table, calculated recovery values for spiked water samples were always greater than $96 \%$, and these results verify the validity of the proposed method.

\section{Conclusion}

An ultrasound-assisted dispersive liquid-liquid microextraction method based on solidification of floating organic drop and back-extraction (UA-DLLME-SFO-BE) technique for lead enrichment in aqueous samples prior to flame atomic absorption determination was reported in this paper. The novelty of the proposed method is the elimination of the clogging problem of the instrument parts caused by frozen 1-dodecanol. In addition, applying ultrasound energy shortens the extraction time and improves the extraction
TABLE 3: Determination of lead ions in several water samples $(n=3)$.

\begin{tabular}{lccc}
\hline Sample & Added $\left(\mu \mathrm{g} \cdot \mathrm{L}^{-1}\right)$ & Found $\left(\mu \mathrm{g} \cdot \mathrm{L}^{-1}\right)$ & Recovery $\%$ \\
\hline \multirow{3}{*}{ Tap water } & 0 & 0 & - \\
& 25.0 & $24.1 \pm 0.9$ & 96.4 \\
& 50.0 & $48.6 \pm 1.3$ & 97.2 \\
Lake water & 100.0 & $98.1 \pm 1.9$ & 98.1 \\
& 0 & $7.6 \pm 0.2$ & - \\
& 25.0 & $31.9 \pm 1.1$ & 97.8 \\
& 50.0 & $56.1 \pm 1.4$ & 97.4 \\
\hline
\end{tabular}

efficiency. Besides known advantages of the conventional SFODME method such as low cost, rapidity, simplicity of operation, high enhancement factor, and extraction efficiency, advantages originated from back-extraction make the proposed method very effective for the determination of trace amounts of lead in natural water samples.

\section{Data Availability}

Data obtained in this research are included in the article.

\section{Conflicts of Interest}

The authors declare that they have no conflicts of interest.

\section{References}

[1] Y. Wang, J. Han, Y. Liu, L. Wang, L. Ni, and X. Tang, "Recyclable non-ligand dual cloud point extraction method for determination of lead in food samples," Food Chemistry, vol. 190, pp. 1130-1136, 2016.

[2] M. Falahnejad, H. Zavvar Mousavi, H. Shirkhanloo, and A. M. Rashidi, "Preconcentration and separation of ultratrace amounts of lead using ultrasound-assisted cloud pointmicro solid phase extraction based on amine functionalized silica aerogel nanoadsorbent," Microchemical Journal, vol. 125, pp. 236-241, 2016.

[3] S. Nekouei, F. Nekouei, I. Tyagi, S. Agarwal, and V. K. Gupta, "Mixed cloud point/solid phase extraction of lead(II) and cadmium(II) in water samples using modified-ZnO nanopowders," Process Safety and Environmental Protection, vol. 99, pp. 175-185, 2016.

[4] S. S. Arain, T. G. Kazi, J. B. Arain, H. I. Afridi, K. D. Brahman, and Naeemullah, "Preconcentration of toxic elements in artificial saliva extract of different smokeless tobacco products by dual-cloud point extraction," Microchemical Journal, vol. 112, pp. 42-49, 2014.

[5] M. Tuzen, K. O. Saygi, and M. Soylak, "Solid phase extraction of heavy metal ions in environmental samples on multiwalled carbon nanotubes," Journal of Hazardous Materials, vol. 152, no. 2, pp. 632-639, 2008.

[6] J. Cao, P. Liang, and R. Liu, "Determination of trace lead in water samples by continuous flow microextraction combined with graphite furnace atomic absorption spectrometry," Journal of Hazardous Materials, vol. 152, no. 3, pp. 910-914, 2008.

[7] A. Szymczycha-Madeja, M. Welna, and P. Pohl, "Comparison and validation of different alternative sample preparation procedures of tea infusions prior to their multi-element analysis by FAAS and ICP-OES," Food Analytical Methods, vol. 9, no. 5, pp. 1398-1411, 2016. 
[8] Ç. Arpa Şahin and İ. Durukan, "Ligandless-solidified floating organic drop microextraction method for the preconcentration of trace amount of cadmium in water samples," Talanta, vol. 85, no. 1, pp. 657-661, 2011.

[9] T. Daşbaşı, Ş. Saçmacı, N. Çankaya, and C. Soykan, “A new synthesis, characterization and application chelating resin for determination of some trace metals in honey samples by FAAS," Food Chemistry, vol. 203, pp. 283-291, 2016.

[10] B. Barfi, M. Rajabi, M. M. Zadeh, M. Ghaedi, M. SalavatiNiasari, and R. Sahraei, "Extraction of ultra-traces of lead, chromium and copper using ruthenium nanoparticles loaded on activated carbon and modified with N,N-bis-( $\alpha$-methylsalicylidene)-2, 2-dimethylpropane-1,3-diamine," Microchimica Acta, vol. 182, no. 5-6, pp. 1187-1196, 2015.

[11] M. Ataee, T. Ahmadi-Jouibari, and N. Fattahi, "Application of microwave-assisted dispersive liquid-liquid microextraction and graphite furnace atomic absorption spectrometry for ultra-trace determination of lead and cadmium in cereals and agricultural products," International Journal of Environmental Analytical Chemistry, vol. 96, no. 3, pp. 271-283, 2016.

[12] R. Rahnama and M. Najafi, "The use of rapidly synergistic cloud point extraction for the separation and preconcentration of trace amounts of $\mathrm{Ni}$ (II) ions from food and water samples coupling with flame atomic absorption spectrometry determination," Environmental Monitoring and Assessment, vol. 188, no. 3, pp. 1-9, 2016.

[13] G. Peng, Q. He, G. Zhou et al., "Determination of heavy metals in water samples using dual-cloud point extraction coupled with inductively coupled plasma mass spectrometry," Analytical Methods, vol. 7, no. 16, pp. 6732-6739, 2015.

[14] L. Zhang, X. Li, X. Wang, W. Wang, X. Wang, and H. Han, "Preconcentration and determination of chromium species by cloud point extraction-flame atomic absorption spectrometry," Analytical Methods, vol. 6, no. 15, pp. 5578-5583, 2014.

[15] M. R. Moghadam, A. M. H. Shabani, and S. Dadfarnia, "Simultaneous spectrophotometric determination of $\mathrm{Fe}(\mathrm{III})$ and $\mathrm{Al}(\mathrm{III})$ using orthogonal signal correction-partial least squares calibration method after solidified floating organic drop microextraction," Spectrochimica Acta Part A: Molecular and Biomolecular Spectroscopy, vol. 135, pp. 929-934, 2015.

[16] C. Arpa Sahin and I. Tokgöz, "A novel solidified floating organic drop microextraction method for preconcentration and determination of copper ions by flow injection flame atomic absorption spectrometry," Analytica Chimica Acta, vol. 667, no. 1-2, pp. 83-87, 2010.

[17] H. Fazelirad and M. A. Taher, "Ligandless, ion pair-based and ultrasound assisted emulsification solidified floating organic drop microextraction for simultaneous preconcentration of ultra-trace amounts of gold and thallium and determination by GFAAS," Talanta, vol. 103, pp. 375-383, 2013.

[18] B. Barfi, A. Asghari, M. Rajabi, and N. Mirkhani, "Dispersive suspended-solidified floating organic droplet microextraction of nonsteroidal anti-inflammatory drugs: comparison of suspended droplet-based and dispersive-based liquid-phase microextraction methods," RSC Advances, vol. 5, no. 129, pp. 106574-106588, 2015.

[19] J. J. Ma, X. Du, J. W. Zhang, J. C. Li, and L. Z. Wang, "Ultrasound-assisted emulsification-microextraction combined with flame atomic absorption spectrometry for determination of trace cadmium in water samples," Talanta, vol. 80, no. 2, pp. 980-984, 2009.

[20] J. Xiong, G. Zhou, Z. Guan, X. Tang, Q. He, and L. Wu, "Determination of chlorpyrifos and its main degradation product tcp in water samples by dispersive liquid -liquid microextraction based on solidification of floatİng organic droplet combined with high-performance liquid chromatography," Journal of Liquid Chromatography \& Related Technologies, vol. 37, no. 11, pp. 1499-1512, 2014.

[21] T. Sismanoglu, S. Pura, and A. S. Bastug, "Binary and ternary metal complexes of Congo red with amino acids," Dyes and Pigments, vol. 70, no. 2, pp. 136-142, 2006.

[22] O. Abollino, M. Aceto, C. Sarzanini, and E. Mentasti, "Behavior of different metal/ligand systems in adsorptive cathodic stripping voltammetry," Electroanalysis, vol. 11, no. 12, pp. 870-878, 1999.

[23] G. Alpdogan, N. San, and F. Dinc Zor, "Analysis of some trace metals in fish species after preconcentration with congo red on amberlite XAD-7 resin by flame atomic absorption spectrometry," Journal of Chemistry, vol. 2016, 8 pages, 2016.

[24] G. Khayatian and S. Hassanpoor, "Development of ultrasound-assisted emulsification solidified floating organic drop microextraction for determination of trace amounts of iron and copper in water, food and rock samples," Journal of Iranian Chemical Society, vol. 10, no. 1, pp. 113-121, 2013.

[25] F. Shemirani, M. Baghdadi, M. Ramezani, and M. R. Jamali, "Determination of ultra trace amounts of bismuth in biological and water samples by electrothermal atomic absorption spectrometry (ET-AAS) after cloud point extraction," Analytica Chimica Acta, vol. 534, no. 1, pp. 163-169, 2005.

[26] I. Durukan, M. Soylak, and M. Doğan, "Enrichment and separation of Fe (III), Mn (II), Ni (II), and Zn (II) as their congo red chelates on multiwalled carbon nanotube (MWCNT) disk in food and water samples," Atomic Spectroscopy, vol. 34, pp. 20-25, 2013.

[27] S. Dadfarnia, A. M. H. Shabani, and A. Mirshamsi, "Solidified floating organic drop microextraction and spectrophotometric determination of vanadium in water samples," Turkish Journal of Chemistry, vol. 35, pp. 625-636, 2011.

[28] İ. Durukan, C. Arpa Sahin, and S. Bektas, "Determination of copper traces in water samples by flow injection-flame atomic absorption spectrometry using a novel solidified floating organic drop microextraction method," Microchemical Journal, vol. 98, no. 2, pp. 215-219, 2011.

[29] M. Leonga, C. Changa, M. Fuhb, and S. Huanga, "Low toxic dispersive liquid-liquid microextraction using halosolvents for extraction of polycyclic aromatic hydrocarbons in water samples," Journal of Chromatography A, vol. 1217, no. 34, pp. 5455-5461, 2010.

[30] S. Bahar and R. Zakerian, "Determination of copper in human hair and tea samples after dispersive liquid-liquid microextraction based on solidification of floating organic drop (DLLME-SFO)," Journal of the Brazilian Chemical Society, vol. 23, no. 6, pp. 1166-1173, 2012. 

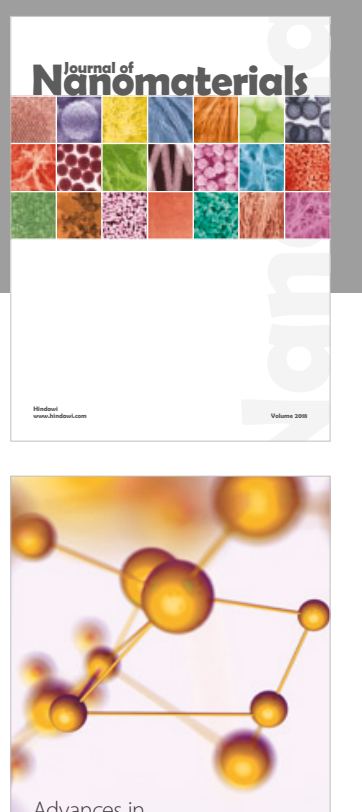

Physical Chemistry
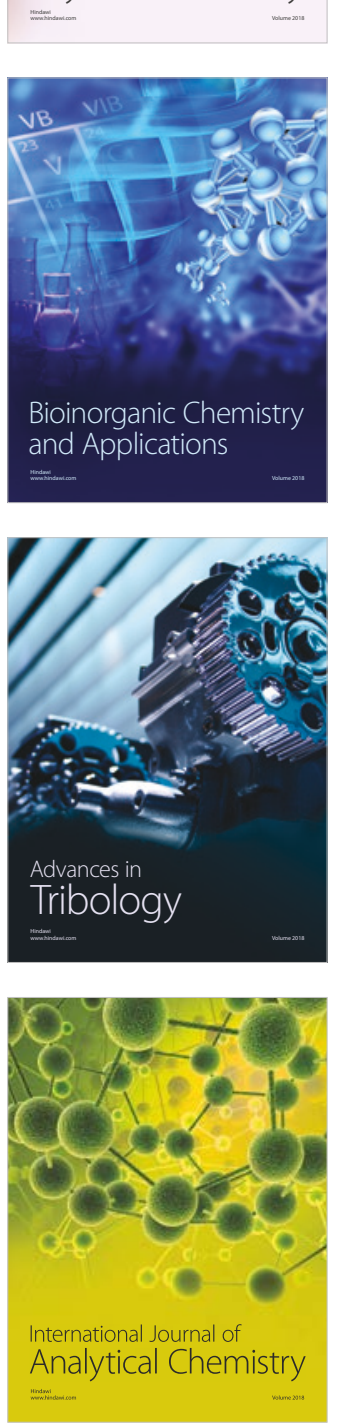

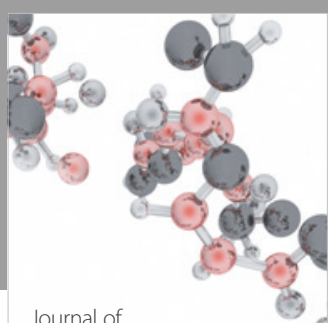

Analytical Methods

in Chemistry

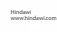

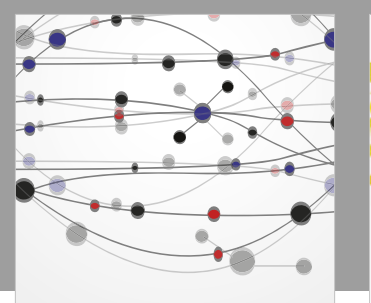

The Scientific World Journal

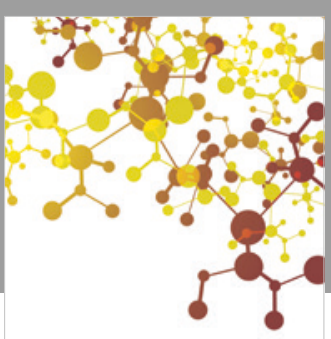

Journal of

Applied Chemistry
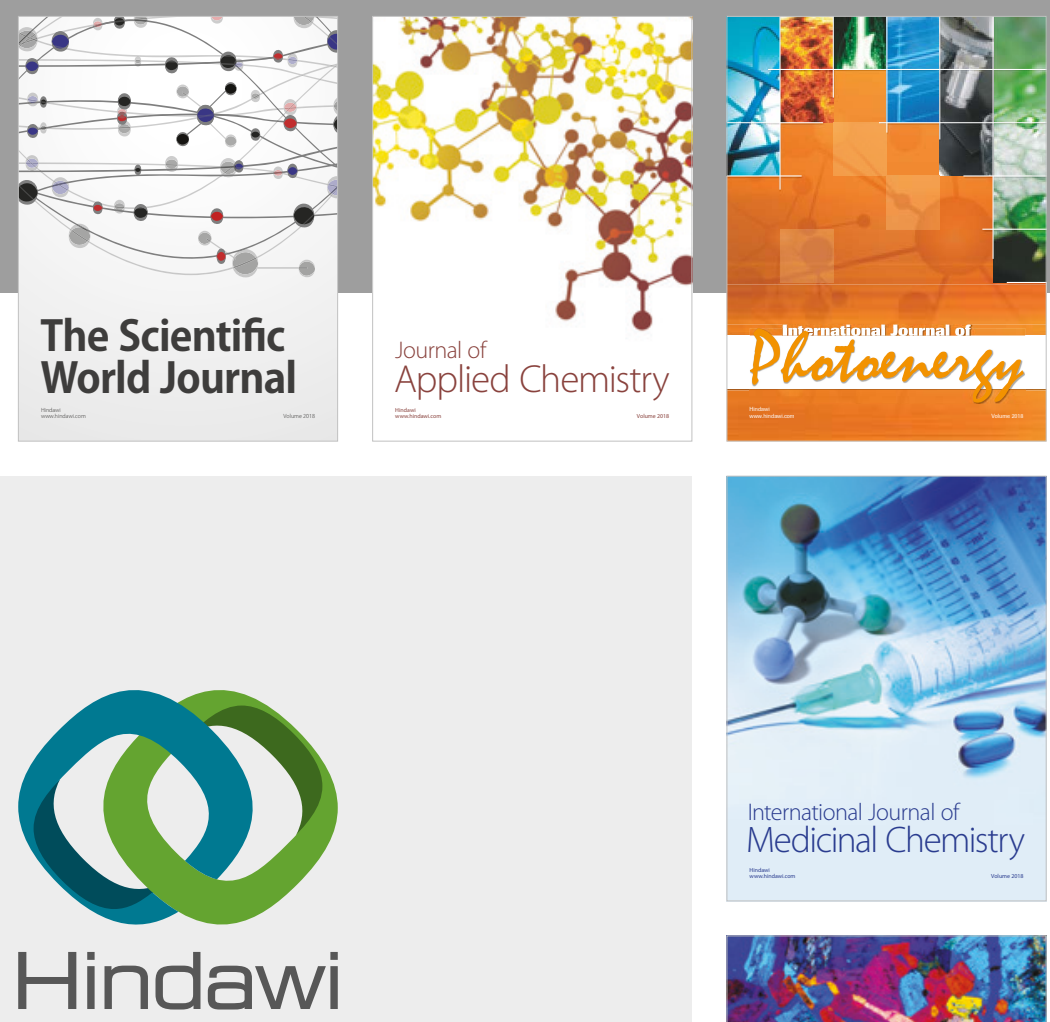

Submit your manuscripts at

www.hindawi.com
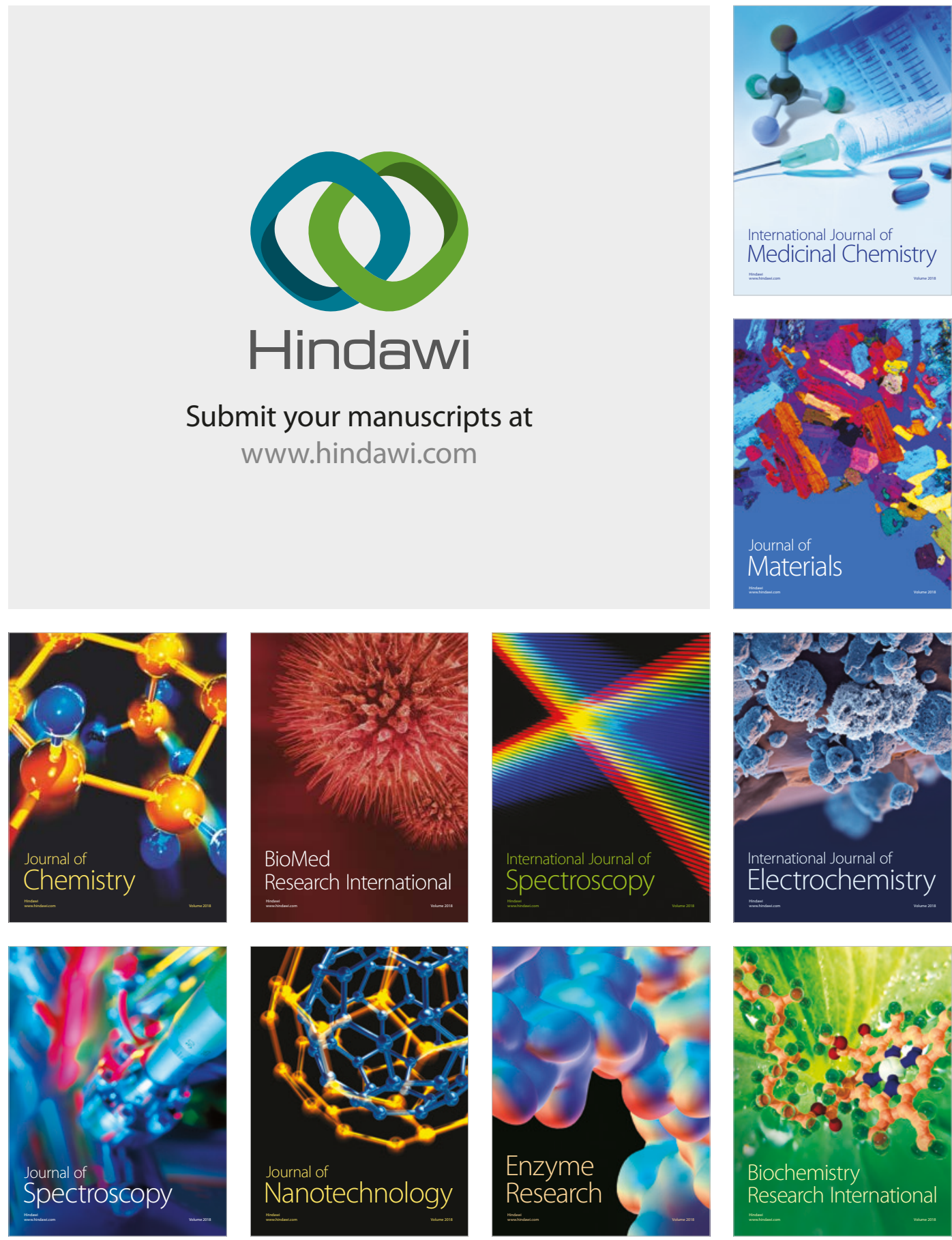
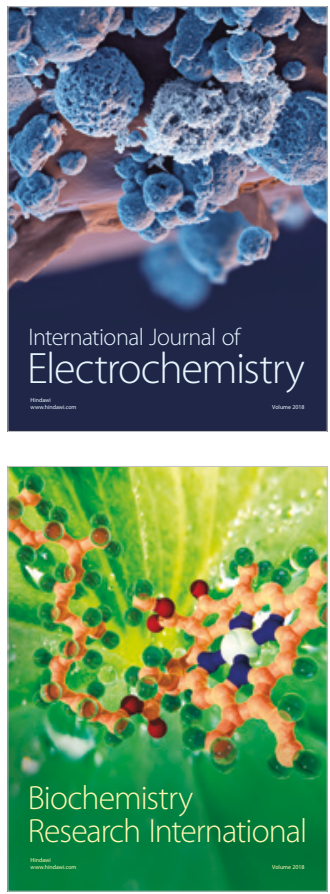